\title{
Cytogenetic Guidelines and Quality Assurance: a common European framework for quality assessment for constitutional and acquired cytogenetic investigations
}

\author{
Ros J Hastings ${ }^{\star 1,5}$, Simona Cavani ${ }^{2,}$, Franca Dagna Bricarelli ${ }^{2,5}$, Philippos C Patsalis ${ }^{3}$, \\ Ulf Kristoffersson $^{4,5}$, and ECA PWG Co-ordinators ${ }^{5}$
}

\author{
${ }^{1}$ UKNEQAS for Clinical Cytogenetics, Women's Centre, John Radcliffe Hospital, Oxford, OX3 9DU, UK; \\ ${ }^{2}$ Laboratory of Genetics, Galliera Hospital, Via A Volta 6, 16128 Genova, Italy; ${ }^{3}$ Department of Cytogenetics, \\ The Cyprus Institute of Neurology and Genetics, POB 23462, 1683 Nicosia, Cyprus; ${ }^{4}$ Department of Clinical Genetics, \\ University Hospital, SE-221 85 Lund, Sweden
}

European Journal of Human Genetics (2007) 15, 525-527. doi:10.1038/sj.ejhg.5201809; published online 14 March 2007

Keywords: cytogenetic guidelines; quality assurance; external quality assessment; best practice

\section{Background}

The Permanent Working Group 'Cytogenetics and Society' of the European Cytogeneticists Association (ECA) prepared Cytogenetic Guidelines and Quality Assurance guidelines as a quality framework for cytogenetic laboratories in Europe in collaboration with EU sponsored Network of Excellence, 'Eurogentest' workpackage 1.4 (external quality assessment in cytogenetics). It is hoped that this document will lead to the establishment of common guidelines and standards that can be used as a reference manual in all European countries. This is particularly applicable to those countries without national guidelines, as they aim to achieve and maintain high standards. The adoption of this document by ECA will facilitate this process.

These cytogenetic guidelines are intended to assist in the development of national standards. Cytogenetic practices and regulations differ throughout Europe; hence in some

${ }^{*}$ Correspondence: Dr RJ Hastings, UKNEQAS for Clinical Cytogenetics, Women's Centre, John Radcliffe Hospital, Oxford, Oxon OX3 9DU, UK. Tel: + 441865 857644; Fax: + 441865 857632;

E-mail: ros.hastings@orh.nhs.uk

${ }^{5}$ These authors were ECA PWG coordinators.

Received 15 December 2006; accepted 2 February 2007; published online 14 March 2007 instances, these guidelines may not be in accordance with national/federal laws and regulations. In such cases, those regulations already form the basis upon which the national standards operate.

These cytogenetic guidelines take into account the existing quality assessment (QA) schemes, good laboratory practice (GLP) documents, accreditation procedures and protocols from different countries, as well as international policy documents. The guidelines also include aspects of quality control and assurance for most of the routine methods currently employed by cytogenetic laboratories. The standards given within the guidelines should be considered as minimum acceptable criteria, and therefore any laboratory consistently operating below the minimum standard may be in danger of failing to maintain a quality service and satisfactory performance over an extended period of time. The guidelines should also be seen as guidance for certification and/or accreditation of cytogenetic laboratories.

\section{Guidelines}

The guidelines cover a wide range of issues, including staffing, workload recommendations reporting times, 
success rates, laboratory procedures, equipment, analysis, interpretation, reporting of results as well as the storage and retention of specimens and documents. Detailed guidance on the techniques and procedures for Constitutional, Oncological (Acquired) and Molecular Cytogenetics (FISH and QF-PCR) is also given. The cytogenetic guidelines include some guidance for difficult issues such as maternal cell contamination, mosaicism, pseudomosaicism, chromosomal variants and substandard analysis.

Quality assurance is an important part of the diagnostic service, and for this reason the guidelines have a separate section devoted to this specific area. Subjects that are covered include the difference between certification and accreditation, internal and external quality control and the examination process involved in accreditation. Additional information is given on the need for appropriate policies and/or documentation for laboratory management and organization, document control, quality manual, health and safety, data protection, confidentiality, training and education to enable a laboratory to become accredited.

One of the major problems for a cytogenetic laboratory is whether to accept all samples sent to the laboratory or to act as a 'gatekeeper' and accept only those samples for which there is a strong indication for cytogenetic analysis. The indications for chromosome analysis in constitutional and acquired cytogenetics given in the appendix of the guidelines will hopefully give support to those cytogenetic laboratories when they act as a 'gatekeeper'.

Finally, the guidelines reference the national and international guidelines, ${ }^{1-10}$ policy documents ${ }^{11-19}$ and other documents consulted in their preparation. As the list is not exhaustive and this is a rapidly changing area in genetics, the guidelines recommend that individuals working in this field continue to keep abreast of the current literature as well as national and international guidelines.

The formation of the European external quality assessment (EQA) network is also strongly endorsed by the authors of the guidelines. While the guidelines are primarily written for diagnostic laboratories, they are equally of interest to EQA providers. As some genetic tests could be performed with a variety of technologies, EQA providers must take this into account when offering EQA schemes/programmes. Such an example could be when looking for small deletions/duplications where FISH analysis or molecular genetic techniques are more appropriate to detect the abnormality than routine chromosomal analysis. Both cytogenetic services and cytogenetic EQAprogrammes must therefore keep up to date with advancing technologies and in some cases this will involve a shift from a cytogenetic to a molecular genetic application. Consequently, in view of the rapidly changing practices and technology in cytogenetics, the guidelines will be revised regularly by the Working Group.

It is hoped that these guidelines will be used by cytogeneticists throughout Europe and may also be of interest to clinical geneticists, molecular geneticists as well as referring clinicians. The guidelines can be found in their entirety on the ECA (www.biologia.uniba.it/eca/) and EuroGentest (www.eurogentest.org) websites.

We acknowledge the contribution of the following individuals to these guidelines: Lorraine Gaunt, Rod Howell, Edna Maltby, Fiona Ross, Sarah Ryley, Zoe Docherty, Susan Gerber, Nils Mandahl and Alain Bernheim. We also thank the following individuals who made comments on this summary document: Nicole Dastague, Martine Doco-Fenzy, Brigitte Faas, Carmen Ramos, Marta Rodriguez de Alba and Joris Vermeesch.

This paper was completed with the support of Eurogentest (Grant No. LSHB-CT-2004-512148).

\section{National Guidelines \\ 1. Australia}

Guidelines for Cytogenetic Laboratories: National Pathology Accreditation Advisory Council - Commonwealth of Australia, 2001.

\section{Belgium}

Guidelines for Clinical Cytogenetic Diagnostic Laboratories in Belgium - Belgium Society of Human Genetics, 2004.

\section{Canada}

CCMG Cytogenetic Guidelines - Canadian College of Medical Genetics, 2003.

\section{France}

Guide De Bonnes Pratiques En Cytogénétique - Association des Cytogénéticiens de Langue Française, 2001; Groupe Français de Cytogénétique Hématologique (GFCH) and the Groupe Français de Cytogénétique Oncologique (GFCO).

\section{Germany}

Berufsverband Medizinische Genetik e.V., Deutsche Gesellschaft für Humangenetik. Leitlinien zur zytogenetischen Labordiagnostik. Medgen 1997; 9: 560-561.

\section{Italy}

Linee guida di Citogenetica: Societa' Italiana di Genetica Umana, 2006.

\section{Sweden}

Riktlinjer før kvalitetssåkring i klinisk genetisk verksamhet 1992, revised 2002 .

\section{The Netherlands}

Kwaliteit van klinisch cytogenetisch onderzoek: voorwaarden, normen en toetsen, 2003.

\section{United Kingdom}

UKNEQAS in Clinical Cytogenetics: Participants' Manual 1999.

UKNEQAS Executive Office: Sheffield.

Professional Guidelines for Clinical Cytogenetics: Professional Standards Working Party of the Association of Clinical Cytogeneticists, 2001, BMJ Publishing group. 
Professional Guidelines for Clinical Cytogenetics: Professional Standards Working Party of the Association of Clinical Cytogeneticists, 2005.

ACC Professional Guidelines - FISH scoring in Oncology, 2005.

ACC Professional Guidelines for Clinical Cytogenetics Prenatal Diagnosis, 2005.

HSC, Advisory Committee on Dangerous Pathogens (ACDP), The management and design and operation of microbial containment laboratories (ISBN 0717620344).

\section{United States}

Standards and Guidelines for Clinical Genetics Laboratories - American College of Medical Genetics, 2003.

\section{International/European standards}

11. EU Directive

- Health and safety at work (89/391/EEC)

- Carcinogens (90/394/EEC)

- Manual Handling (90/269/EEC)

- Safety signs (92/58/EEC)
- Pregnant workers (92/85/EEC)

- Use of protective equipment $(91 / 383 / \mathrm{EEC})$

12. ISO 17025:2005: General requirements for the competence of testing and calibration laboratories.

13. ISO 15189:2003. Medical Laboratories - particular requirements for quality and competence.

14. ISO/IEC Guide 2 General terms and their definitions concerning standardization and related activity.

15. Freedom of Information Act 2000.

16. Data Protection Act 1998.

17. Convention for the protection of Human Rights and dignity of the human being with regard to the application of biology and medicine: convention on human rights and biomedicine, Oviedo, 1999.

18. ISCN. In: Shaffer LG, Tommerup $\mathrm{N}$ (eds). An International System for Human Cytogenetic Nomenclature, Basel: S Karger, 2005.

19. ICD-10; International Classification of disease. WHO. 